\title{
Synthesis of New Polyfunctional Cage Oligosilsesquioxanes and Cyclic Siloxanes by Thiol-ene Addition
}

\author{
K. Rózga-Wijas $\cdot$ J. Chojnowski
}

Received: 1 December 2011/Accepted: 9 January 2012/Published online: 5 February 2012

(c) The Author(s) 2012. This article is published with open access at Springerlink.com

\begin{abstract}
A novel octakis-2\{[3-(trimethoxysilyl)propyl] thio \}ethyl-octasilsesqioxane (POSS-M24) was synthesized by radical thiol-ene addition of 3-mercaptopropyltrimethoxysilane, (MPTMS) to octavinyloctasilsesquioxane, (POSS-V8) in the presence of $2,2^{\prime}$ azobisisobutyronitryl under mild conditions $\left(60{ }^{\circ} \mathrm{C}\right.$, toluene solution). Nano-building POSS units bearing both types of groups, 2-[3-(trimethoxysilyl)propylthio]-ethyl and vinyl, pendant to the POSS-cage were obtained by partial addition of MPTMS to the vinyl functions. Finally the thiol-ene addition of MPTMS to 2,4,6-trivinyl-2,4,6-trimethylcyclotrisiloxane $\left(\mathrm{V}_{3}\right)$ and 2,4,6,8-tetravinyl-2,4,6,8-tetramethylcyclotetrasiloxane $\left(\mathrm{V}_{4}\right)$ were explored. The structures of the thiol-ene addition products were confirmed by ${ }^{29} \mathrm{Si} \mathrm{NMR}$ and mass Spectroscopy.
\end{abstract}

Keywords Thiol-ene addition - Oligosilsesquioxane · Cyclosiloxanes · POSS · Functionalized POSS ·

3-mercaptopropyltrimethoxysilane

\section{Introduction}

Polyfunctional cage polyhedral oligosilsesquioxanes (POSSs) and polyfunctional cyclic oligosiloxanes could be used as precious reactants in the synthesis of various polymers and precursors of new materials. They may serve as cores for the generation of star branched, hyperbranched

This paper is dedicated to Professor Jim Mark in recognition of his great contribution to polymer and material chemistry.

K. Rózga-Wijas $(\bowtie) \cdot J$. Chojnowski

Centre of Molecular and Macromolecular Studies, Polish

Academy of Sciences, Sienkiewicza 112, 90-363 Łódź, Poland

e-mail: krysia@cbmm.lodz.pl and dendritic branched polymers [1-3] and may be used for the cross-linking of linear polymers to produce various polymer networks [4-7]. They may also be important precursors in sol-gel technology for the generation of various porous and bulk materials [8-11]. Cage polysilsesquioxanes of regular polyhedral structure bearing many functional groups are used for the construction of composite materials for various applications such as catalysts, nano-reactors, sensors, metal absorption [12-15] etc. $[16,17]$.

The subject of this paper is the synthesis of polyhedral silsesquioxanes having many alkoxysilyl functions or mixed vinylsilyl and alkoxysilyl functions. Our research is extended to some cyclic oligosiloxanes bearing alkoxysilyl groups. These new POSSs and cyclosiloxanes will be used as reactants in heterofunctional polycondensation and solgel hydrolytic polycondensation of alkoxy groups. Alkoxy functional silane and siloxanes are commonly used in these reactions [18-21].

The synthetic method for the target compounds is the thiolene addition of (3-mercaptopropyl)trimethoxysilane (MPTMS) to vinyl groups bonded to silicon in octahedral octa-vinyloctasilsesquioxane (POSS-V8), 2,4,6-trivinyltrimethylcyclotrisiloxane $\left(\mathrm{V}_{3}\right)$ and 2,4,6,8-tetravinyltetramethylcyclotetra siloxane $\left(\mathrm{V}_{4}\right)$. MPTMS is a commercially available product commonly used as a promoter of adhesion [22-24]. Thiol-ene addition is a convenient route to functionalized POSSs and cyclic siloxanes. This reaction proceeds by a free radical mechanism and uses classical initiators of radical reactions such as peroxides or diazo compounds. No ionic or acid-base active compounds are present in the polymerization system, which could cleave siloxane bond and destroy the POSS or cyclic siloxane structure. This method avoids metal catalysts, which could contaminate the addition product. The additional advantage of the thiol-ene addition is that it introduces thioether 
functions to the product, which may be further modified [25]. Thiol-ene addition has been successively used for the synthesis of functionalized carbosilane dendrimers [26, 27]. This reaction was also proved to be useful for the functionalization of POSSes [6, 28-31] and polysiloxanes [32-36]. Two different strategies were used for this purpose. A thiol substituted POSS or polysiloxane were submitted to the reaction with an alkene [13, 30, 36]. The reverse method, i.e. the addition of a thiol to alkene-POSS or polysiloxane, which is used in this research, was also practiced [6, 28, 29, 31-35].

\section{Results and Discussion}

The thiol-ene addition of 3-mercaptopropyltrimethoxysilane (MPTMS) to a vinyl group that is bonded to silicon in the structure of silsesquioxane cage or in the siloxane ring was explored. The reaction, initiated by 2,2'azobisisobutyronitryl (AIBN), proceeded according to free radical mechanism. In all cases studied here the addition mostly conformed to the anti-Markovnikov rule. The reaction was performed in a toluene solution using $8-10 \mathrm{~mol} \%$ excess of MPTMS to ensure the full conversion of vinyl groups. The addition proceeded fairly rapidly under mild conditions. The full addition was achieved after about $3-\mathrm{h}$ at $60^{\circ} \mathrm{C}$. Proton NMR spectroscopy is a good tool for the control of the conversion of vinyl group. Since the yield of the silsesquioxane and siloxane was a fully substituted product, the products were isolated after evaporation of the solvent and excess MPTMS at high vacuum. The products were viscous liquids, which were pure by ${ }^{1} \mathrm{H}$ NMR analysis. The thiol-ene addition allows the synthesis of the thioether product having a controlled average degree of the conversion of vinyl groups in a substrate by using a suitable molar ratio of the thiol to ene reagents.

\subsection{Synthesis and Structural Characterization of the Organosilsesquioxane}

The synthesis of polyalkoxy functional octasilsesquioxanes is illustrated in Scheme 1 and the polyalkoxy functional cyclic siloxanes in Scheme 2.

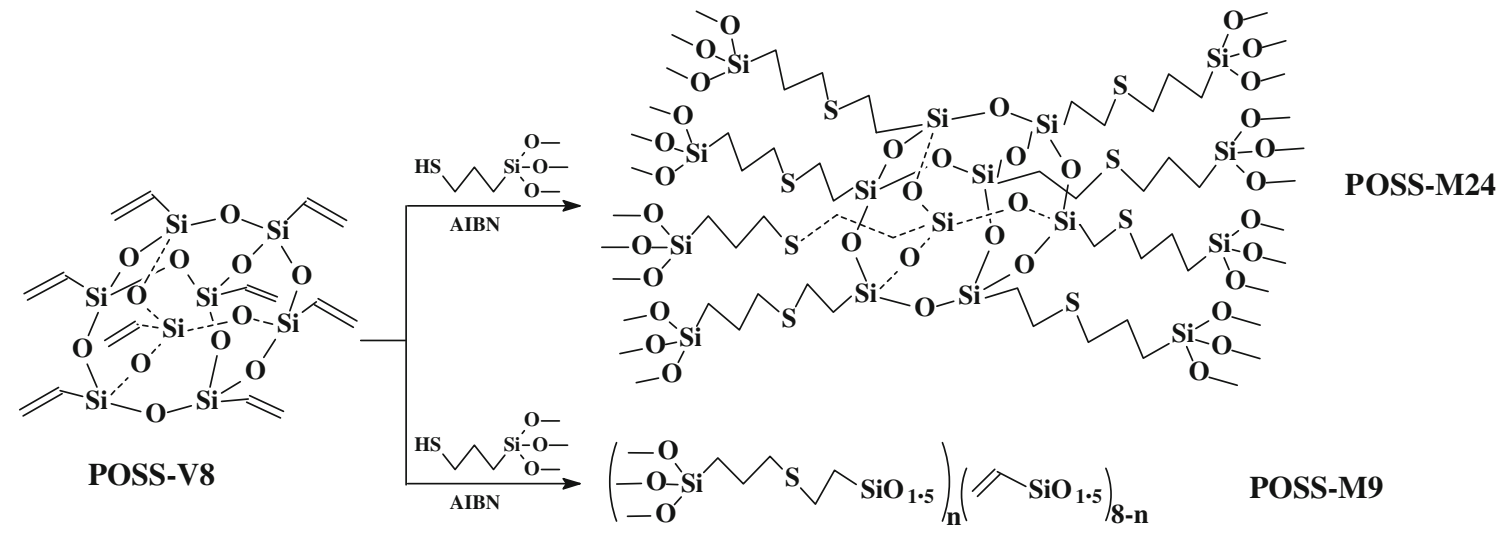

Scheme 1 The thiol-ene addition of MPTMS to octavinyloctasilsesquioxane

Scheme 2 The thiol-ene addition of MPTMS to vinyl substituted oligocyclosiloxanes

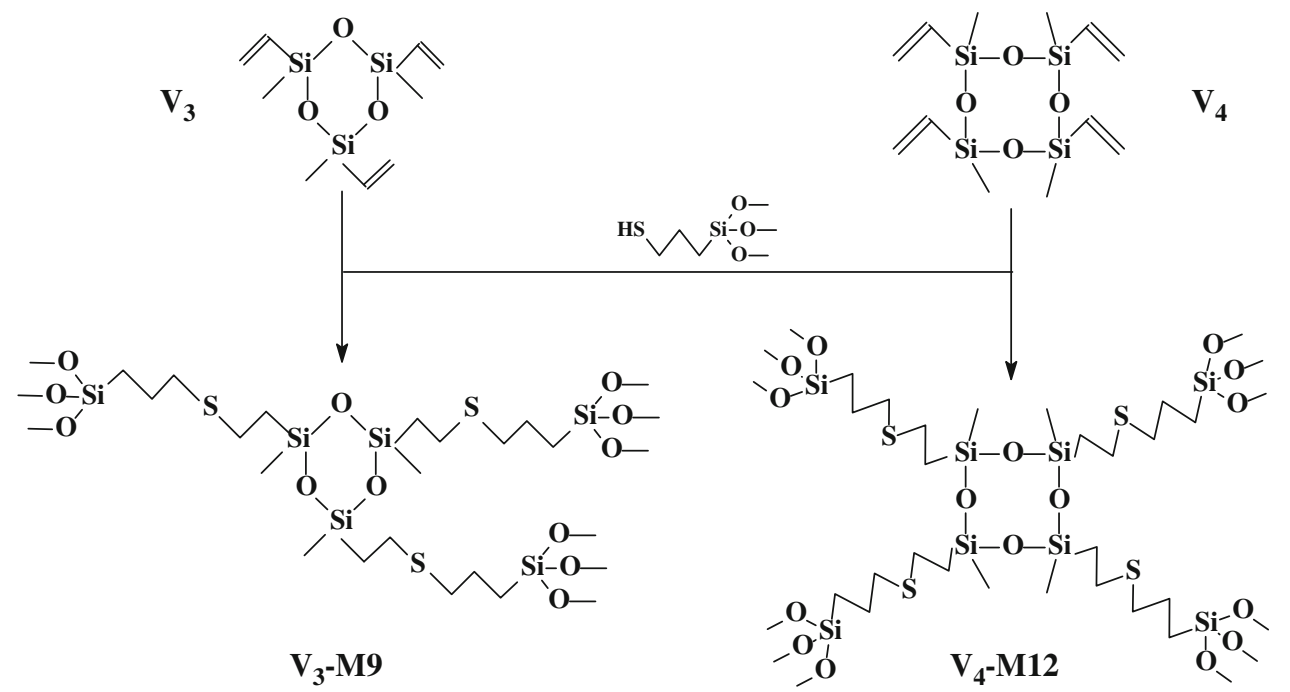


The progress of thiol addition to the carbon-carbon unsaturated bond may be followed by ${ }^{1} \mathrm{H}$ NMR as it is accompanied by the disappearance of the vinyl group signal at $6.02 \mathrm{ppm}$, the shift of the resonance of $\mathrm{OCH}_{3}$ protons from $3.40 \mathrm{ppm}$ in the substrate to $3.47 \mathrm{ppm}$ in the product and by the formation of two new multiplets centered at 2.49 and 2.70 ppm due to the thioether bridge, $\mathrm{CH}_{2}-\mathrm{S}-\mathrm{CH}_{2}$ (Fig. 1).

The confirmation of the full preservation of the POSS cage structure in the tiol-ene addition comes from the ${ }^{29} \mathrm{Si}$ NMR spectrum of the addition product (Fig. 2). There are two sharps signals in this spectrum; one at $-68.36 \mathrm{ppm}$, which represents the resonance of eight silicon atoms of the

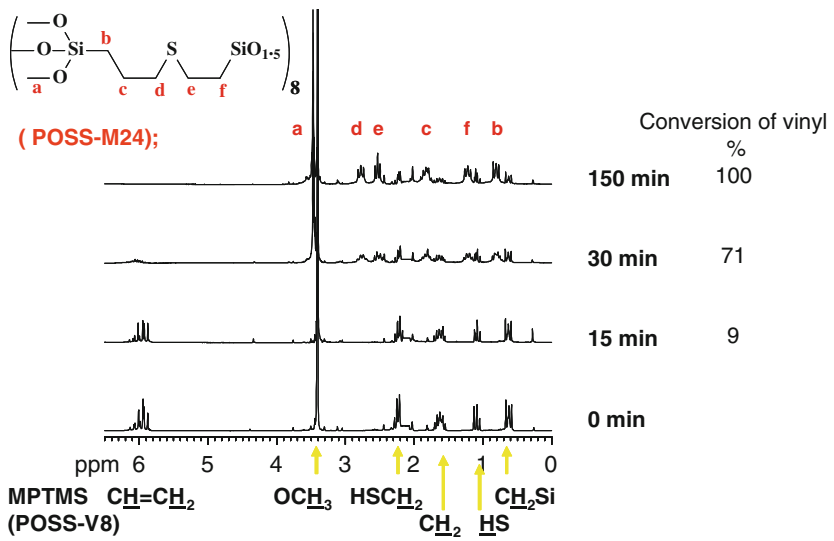

Fig. 1 Variation of the ${ }^{1} \mathrm{H}$ NMR spectrum of the reaction mixture, POSS-V8 with MPTMS, in deuterated toluene at $60{ }^{\circ} \mathrm{C}$ using $8 \mathrm{~mol}$ $\%$ excess of the HS reagent. POSS-M24 is marked by letters on the formula placed above the spectrum. Signals belonging to the substrates are marked by arrows under the chemical shift axis

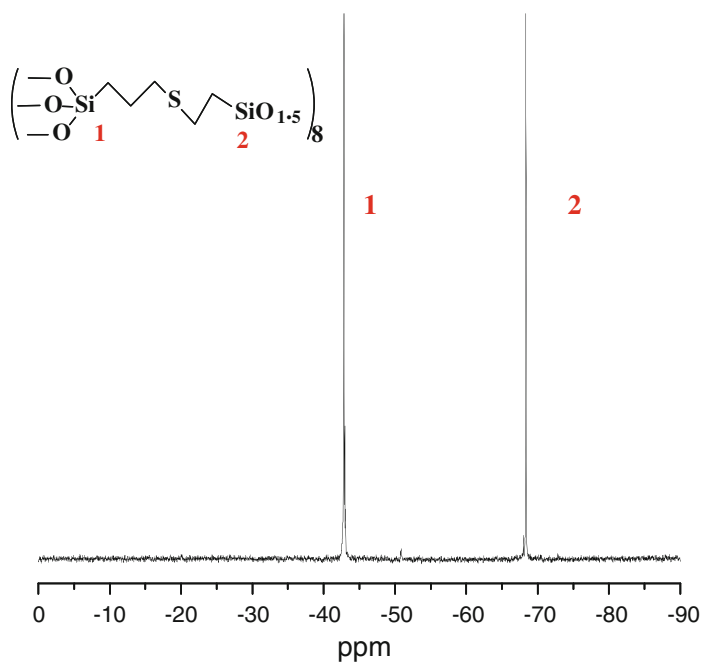

Fig. $2{ }^{29} \mathrm{Si}$ NMR spectrum of the octakis-2\{[3-(trimethoxysilyl)propyl]thio \}ethyl-octasilsesqioxane, POSS-M24. The spectrum was taken in $\mathrm{C}_{6} \mathrm{D}_{6}$ by the invgate technique

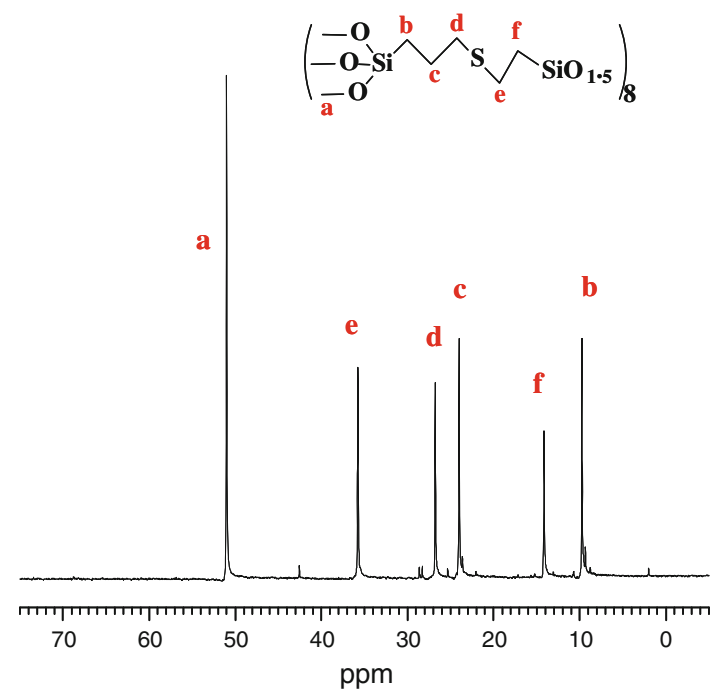

Fig. $3{ }^{13} \mathrm{C}$ NMR spectrum of POSS-M24 in $\mathrm{CDCl}_{3}$

POSS cage, and one at $-42.82 \mathrm{ppm}$ belonging to eight $\mathrm{Si}$-atoms bearing alkoxy groups.

Confirmation of the POSS-M24 structure is provided by the ${ }^{13} \mathrm{C}$ NMR spectrum, which exhibits, exclusively, sharp signals for carbon belonging to the fully converted vinyl groups in the MPTMS addition to octavinyloctasilsesquioxane (Fig. 3).

The mass spectrum of POSS-M24 (chemical ionization technique) is shown in Fig. 4. The $M+1$ peak appears at $m / z=2203.2 \mathrm{~g} / \mathrm{mol}$, which is in a fair agreement with molar mass of the protonated species taking the isotope effect into consideration (i.e., $M=2203.73$ ). This peak is saturated by the $\mathrm{M}+1-31$ peak of the cationic fragment of POSS-M24 after cleavage of $\mathrm{MeOH}$ from the protonated form. The fragmentation occurs also by cleavage of the all organic group from the silicon atom of the cage, which is marked by the signal at $\mathrm{m} / z=1978 \mathrm{~g} / \mathrm{mol}$. The peak at $m / z=2008.4$ results from the cleavage of MPTMS from protonated POSS-M24, while $m / z=2040 \mathrm{~g} / \mathrm{mol}$ is attributed to the ion that is fragmented after cleavage of $\mathrm{CH}_{3} \mathrm{CH}_{2} \mathrm{CH}_{2} \mathrm{Si}\left(\mathrm{OCH}_{3}\right)_{3}$ from $\mathrm{H}^{+}$POSS-M24.

Octasilsesquioxane POSSs containing both vinyl and trimethoxysilyl functions are obtained by the partial addition of MPTMS to POSS-V8. The average ratio of both functions in the POSS product may be roughly controlled by the initial ratio of the substrates concentrations. The POSS product having an average five vinyl groups and 3-trimethoxysilyl groups POSS-M9 was generated using an initial MPTMS-toPOSS-V8 molar ratio of 3:1. The addition was performed for a longer time to achieve the full conversion of MPTMS, which was confirmed by the disappearance of the thiol group ${ }^{1} \mathrm{H}$ NMR signal in the reaction mixture. The product is a mixture of POSSs with various numbers of unreacted vinyl groups, the average of which is 5 . 
Fig. 4 Mass spectrum of POSS-M24

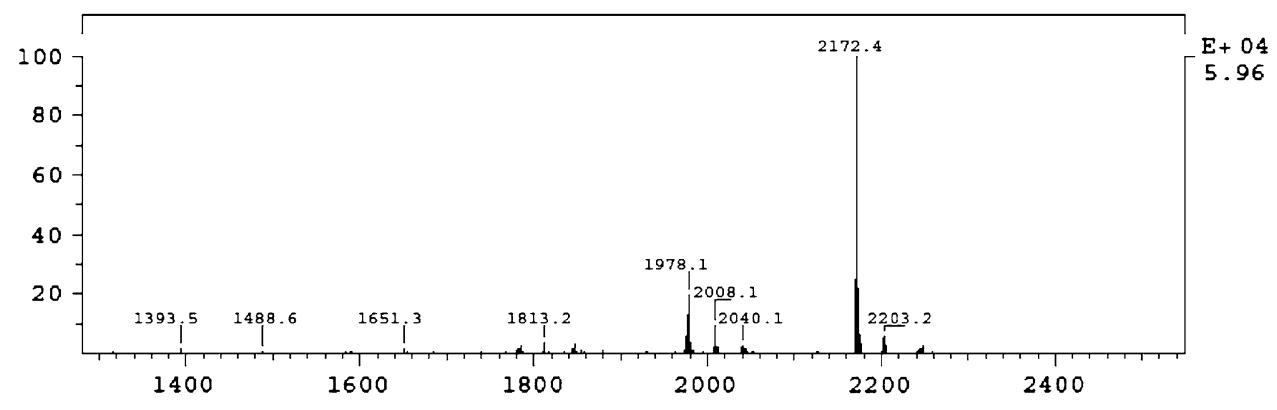

A

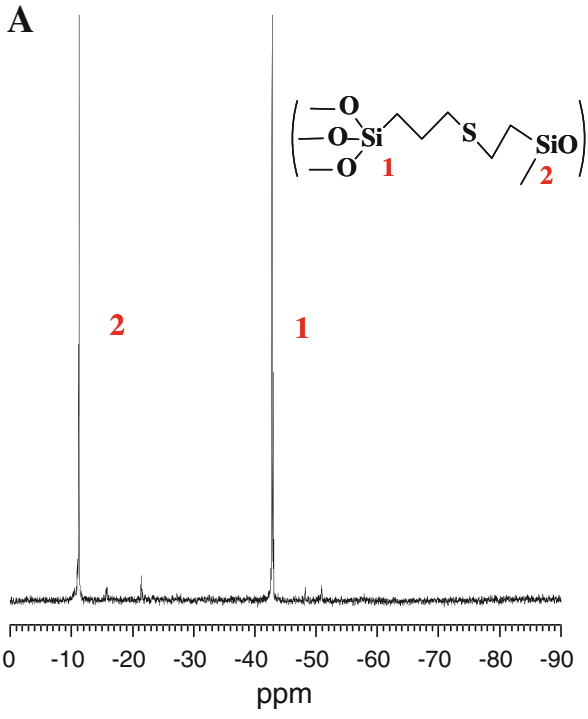

Fig. $5{ }^{29} \mathrm{Si}$ NMR spectra of the a tris-2,4,6-2\{[3-(trimetoksysilyl)propyl]thio ethyl-2,4,6-trimethylcyclotrisiloxane ( $\mathrm{V}_{3}$-M9) and b tetrakis-2,4,6,8-2\{[3-(trimetoksysilyl)propyl]thio $\}$ ethyl-2,4,6,8-

\subsection{Addition of MPTMS to Vinyl Substituted \\ Oligocyclosiloxanes}

Two vinyl substituted oligocyclosiloxanes were used as substrates in the thiol-ene addition of MPTMS; i.e., ring strained 2,4,6-trivinyl-2,4,6-trimethylcyclotrisiloxane $\left(\mathrm{V}_{3}\right)$ and the strain free 2,4,6,8-tetravinyl-2,4,6,8-tetramethylcyclotetrasiloxane $\left(\mathrm{V}_{4}\right)$. Both species are mixture of stereoizomers. The reaction was initiated by AIBN in toluene at $60{ }^{\circ} \mathrm{C}$ and proceeds to the full conversion of vinyl groups in a relatively short time (5-h) with a small molar excess $(8 \%)$ of MPTMS. The ring structure of cyclosiloxanes, even the strained one, was fully preserved in the reaction which was confirmed by ${ }^{29} \mathrm{Si}$ NMR spectra (Fig. 5a, b). The course of the addition may be monitored by ${ }^{1} \mathrm{H}$ NMR in an analogous manner to that for POSS-V8. The spectrum of the addition to $\mathrm{V}_{4}$ product is shown in Fig. 6.

The MS CI spectrum of the product $\mathrm{V}_{4}-\mathrm{M} 12$ from the addition of MPTMS to $\mathrm{V}_{4}$ is shown in Fig. 7. The
B

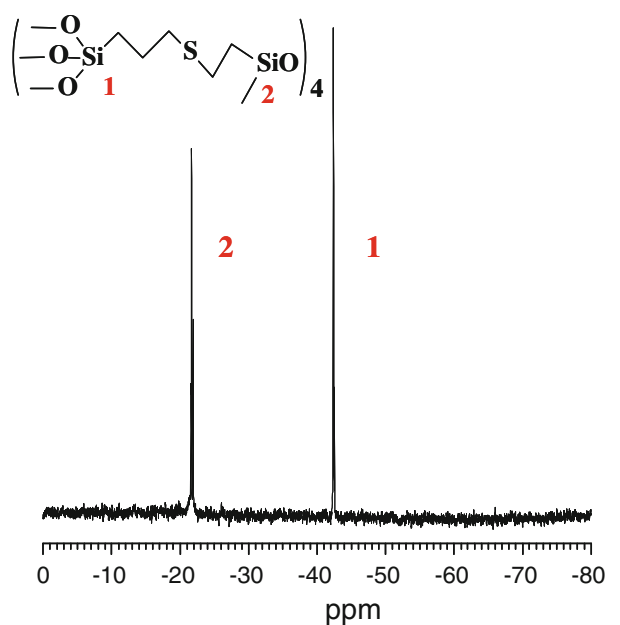

tetramethylcyclotetrasiloxane $\left(\mathrm{V}_{4}-\mathrm{M} 12\right)$. The spectra ware taken in $\mathrm{C}_{6} \mathrm{D}_{6}$ by the invgate technique

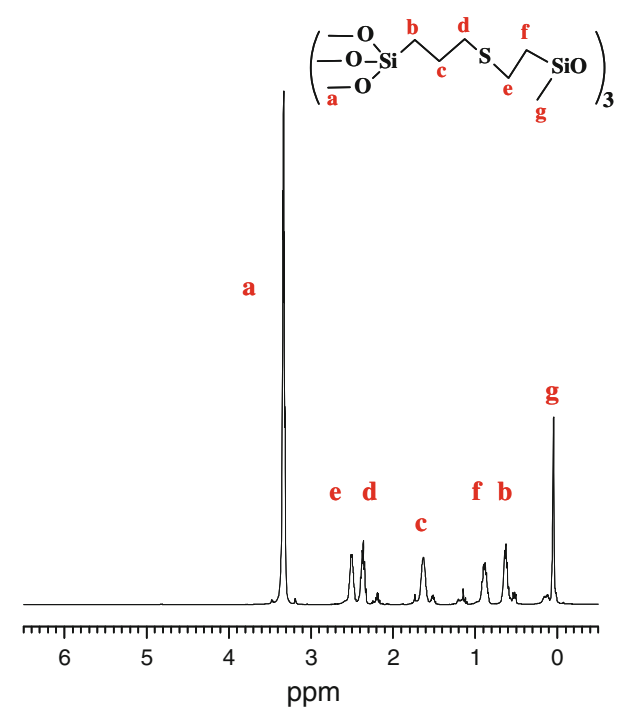

Fig. $6{ }^{1} \mathrm{H}$ NMR spectrum of $\mathrm{V}_{3}-\mathrm{M} 9$, the product of addition of MPTMS to $V_{3}$ in $C_{6} D_{6}$ 


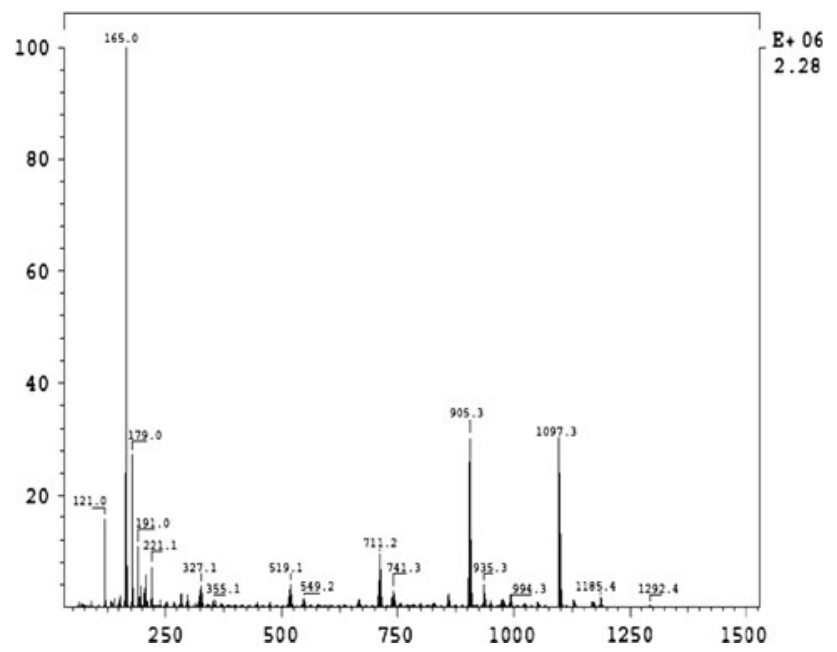

Fig. 7 MS CI spectrum of $\mathrm{V}_{4}-\mathrm{M} 12$

dominant peak is $\mathbf{M}+1-31$ at $\mathrm{m} / z=1097.3$ and represents the $\mathrm{V}_{4}$-M12 fragment after cleavage of methanol from the protonated species. The mother peak +1 appears at $m / z=1128$.

The thermally initiated thiol-ene addition is a simple and efficient method for the polyfunctionalization with alkoxy groups of both cage oligosilsesquioxanes as well as cyclic oligosiloxanes. This method permits to synthesize these important silicon precursors of variety of materials in mild conditions and with almost theoretical yield. The product is not contaminated with a metal or ionic impurity. It is worth to mention that the radical thiol-ene addition may be also initiated photochemically [28-30] which gives additional advantages allowing to avoid impurities originating from the decomposition of radical initiator and giving the possibility of the modification of surfaces.

The new polyfunctionalized oligosilsesquioxanes and oligosiloxanes synthesized here will be further used in syntheses of gel nanocomposites by sol-gel method and in the modification of silicone elastomers.

\section{Experimental}

\subsection{Analytical Methods}

${ }^{1} \mathrm{H},{ }^{13} \mathrm{C}$ and ${ }^{29} \mathrm{Si}$ nuclear magnetic resonance NMR spectra were recorded with a Brucker AVANCE III DRX-500 MHz spectrometer using $\mathrm{CDCl}_{3}$ or $\mathrm{C}_{6} \mathrm{D}_{6}$ as solvents. Spectrometer operating frequencies were $500.13 \mathrm{MHz}\left({ }^{1} \mathrm{H}\right)$, 125.77 MHz $\left({ }^{13} \mathrm{C}\right)$ and $99.36 \mathrm{MHz}\left({ }^{29} \mathrm{Si}\right)$. Tetramethylsilane was used as an internal standard. Quantitative integration of ${ }^{29} \mathrm{Si}$ NMR spectra was achieved using the inverse-gated decoupling technique. A pulse delay of 15-s was usually applied and a typical pulse length was $15-\mu$ s. Elemental analyses for $\mathrm{C}, \mathrm{H}$ and $\mathrm{S}$ were performed using a Euro EA elemental analyzer made by Euro Vector Instruments \& Software. Mass spectra were recorded with a GCMS Finnigan MAT 95 instrument using the chemical ionization technique by passing the sample into ionization chamber by direct inlet. The reactive gas $(\mathrm{H}+$ carrier $)$ was isobutane at a pressure of $10^{-4} \mathrm{mmHg}$.

\subsection{Chemicals}

Toluene (analytical grade; POCH S.A.) was dried by distillation under argon from sodium and kept in an ampoule equipped with Rotaflo stopcock. Octavinyloctasilsesquioxane (POSS-V8), 3-Mercaptopropyltrimethoxysilane (MPTMS) $99 \%$ and 2,4,6,8-tetravinyl-2,4,6,8-tetramethylcyclotetrasil oxane $\left(\mathrm{V}_{4} ; 97 \%\right)$ were reagent grade from ABCR-Gelest. 2,4,6-Trivinyl-2,4,6-trimethylcyclotrisiloxane $\left(\mathrm{V}_{3}\right)$ was prepared by reacting vinylmethyldichlorosilane with zinc oxide [37]. The purity (96\%) was checked by gas chromatography. AIBN was obtained from Aldrich and was used without purification.

\subsection{Synthesis of Octakis-2\{[3-(trimetoksysilyl) propyl]thio ethyl-octasilsesquioxane (POSS-M24)}

Octavinyloctasilsesquioxane (POSS-V8, $3.8 \mathrm{~g}, 0.006 \mathrm{~mol}$ ), AIBN $\left(0.017 \mathrm{~g}, 1 \times 10^{-4} \mathrm{~mol}\right)$ and toluene $(10 \mathrm{~mL})$ were placed in a $30 \mathrm{~mL}$ glass reactor equipped with a magnetic stirrer and purged with a pure argon. The mixture was heated gently to $40{ }^{\circ} \mathrm{C}$ and MPTMS (10.21 g, $0.052 \mathrm{~mol}$ ) was introduced drop-wise. The stirring was continued at $60{ }^{\circ} \mathrm{C}$ for 3-h. The course of the thiol-ene addition was controlled by sampling and ${ }^{1} \mathrm{H}$ NMR analysis. Evaporation of solvent and excess MPTMS under reduced pressure gave octakis$2\{[3$-(trimetoksysilyl)propyl]thio\}ethyl-octasilsesquioxane (POSS-M24, $13.22 \mathrm{~g}$, yield $100 \%) .{ }^{29} \mathrm{Si}$ NMR $\left(\mathrm{C}_{6} \mathrm{D}_{6}\right) \delta$ (ppm): $-42.82\left(\mathrm{~s}, \mathrm{Si}-\mathrm{OCH}_{3}\right),-68.36\left(\mathrm{~s}, \mathrm{SiO}_{1.5}-\mathrm{CH}_{2}\right) ;{ }^{1} \mathrm{H}$ $\operatorname{NMR}\left(\mathrm{C}_{6} \mathrm{D}_{6}\right) \delta$ (ppm): $0.75\left(\mathrm{t}, 16 \mathrm{H}, \mathrm{CH}_{2}-\mathrm{Si}-\mathrm{OCH}_{3}\right), 1.15$ (m, $\left.16 \mathrm{H}, \mathrm{CH}_{2}-\mathrm{SiO}_{1.5}\right), 1.76\left(\mathrm{~m}, 16 \mathrm{H}, \mathrm{CH}_{2}-\mathrm{CH}_{2}-\mathrm{CH}_{2}\right), 2.49$ (t, 16H, $\left.\underline{\mathrm{CH}}_{2}-\mathrm{S}\right), 2.70$ (t, 16H, S- $\left.\underline{\mathrm{CH}}_{2}\right), 3.47\left(\mathrm{~s}, 72 \mathrm{H}, \mathrm{CH}_{3} \mathrm{O}-\right.$ $\mathrm{Si}) ;{ }^{13} \mathrm{C} \overline{\mathrm{N}} \mathrm{RR}\left(\mathrm{CDCl}_{3}\right) \delta(\mathrm{ppm}): 8.39\left(\mathrm{CH}_{2}-\mathrm{Si}-\mathrm{OCH}_{3}\right)$, $12.84\left(\mathrm{CH}_{2}-\mathrm{SiO}_{1.5}\right), 22.62\left(\mathrm{CH}_{2} \mathrm{CH}_{2} \mathrm{CH}_{2}\right), 25.61\left(\mathrm{~S}-\mathrm{CH}_{2}\right)$, $34.58\left(\underline{\mathrm{CH}}_{2}-\mathrm{S}\right), 50.31\left(\mathrm{CH}_{3} \mathrm{O}-\mathrm{Si}\right)$. Elemental Analysis: calc. (\%) for $\mathrm{C}_{64} \mathrm{H}_{152} \mathrm{O}_{36} \mathrm{~S}_{8} \mathrm{Si}_{16}$ (2203.7): C, 34.88; H, 6.95; S, 11.64; found: C, 36.21; H, 6.57; S, 11.25.

\subsection{Synthesis of Tetrakis 2,4,6,8-2}

\{[3-(trimetoksysilyl)propyl]thio \}ethyl-2,4,6, 8-tetramethylcyclotetrasiloxane $\left(\mathrm{V}_{4}-\mathrm{M} 12\right)$ :

Addition of MPTMS to 2,4,6,8-tetravinyl-2,4,6,8-tetramethylcyclotetrasiloxane $\left(\mathrm{V}_{4}\right)$ was performed in analogous way to that described above. Stirring of $\mathrm{V}_{4}(6.89 \mathrm{~g}, 0.02 \mathrm{~mol})$, MPTMS (17.28 g, $0.088 \mathrm{~mol})$, AIBN (0.02 g) in toluene 
(8 mL) gave $\mathrm{V}_{4}$-M12 (22.6 g, theoretical yield). ${ }^{29} \mathrm{Si}$ NMR $\left(\mathrm{CDCl}_{3}\right) \delta(\mathrm{ppm}):-21.65\left(\mathrm{~s}, \mathrm{CH}_{3} \mathrm{Si}\right),-42.38\left(\mathrm{~s}, \mathrm{Si}-\mathrm{OCH}_{3}\right)$; ${ }^{1} \mathrm{HNMR}\left(\mathrm{CDCl}_{3}\right) \delta(\mathrm{ppm}): 0.06\left(\mathrm{~s}, 12 \mathrm{H}, \mathrm{CH}_{3}-\mathrm{Si}\right) 0.65(\mathrm{~m}, 8 \mathrm{H}$, $\left.\mathrm{CH}_{2}-\mathrm{Si}-\mathrm{OCH}_{3}\right), 0.81\left(\mathrm{~m}, 8 \mathrm{H}, \mathrm{CH}_{2}-\mathrm{SiO}_{2}\right), 1.59\left(\mathrm{~m}, 8 \mathrm{H}, \mathrm{CH}_{2}-\right.$ $\left.\overline{\mathrm{CH}}_{2}-\mathrm{CH}_{2}\right), 2.47\left(\mathrm{~m}, 16 \mathrm{H}, \mathrm{CH}_{2}-\overline{\mathrm{S}} \times 2\right), 3.47\left(\mathrm{~s}, 36 \mathrm{H}, \mathrm{CH}_{3} \mathrm{O}-\right.$ $\mathrm{Si}),{ }^{13} \mathrm{C}$ NMR $\left(\mathrm{CDCl}_{3}\right) \delta$ (ppm): $-0.78\left(\mathrm{CH}_{3} \mathrm{SiO}_{2}\right), 8.34$ $\left(\mathrm{CH}_{2}-\mathrm{Si}-\mathrm{OCH}_{3}\right), 17.62\left(\mathrm{CH}_{2}-\mathrm{SiO}_{2}\right), 22.58\left(\mathrm{CH}_{2} \mathrm{CH}_{2} \mathrm{CH}_{2}\right)$, $25.88\left(\mathrm{~S}-\mathrm{CH}_{2}\right), 34.56\left(\mathrm{CH}_{2}-\mathrm{S}\right), 50.23\left(\mathrm{CH}_{3} \mathrm{O}-\mathrm{Si}\right)$. Elemental Analysis: calc. (\%) for $\overline{\mathrm{C}}_{36} \mathrm{H}_{88} \mathrm{O}_{16} \mathrm{~S}_{4} \mathrm{Si}_{8}$ (1130.0): C, 38.26; $\mathrm{H}$, 7.85; S, 11.35; found: C, 38.05; H, 6.31; S, 11.38 .

3.5 Synthesis of Tetrakis2,4,6-2\{[3-(trimetoksysilyl) propyl]thio ethyl-2,4,6-trimethylcyclotrisiloxane $\left(\mathrm{V}_{3}\right.$-M9):

$\mathrm{V}_{3}$-M9 was synthesized as above from $\mathrm{V}_{3}(2.58 \mathrm{~g}, 0.01 \mathrm{~mol})$, MPTMS (6.48 g, $0.033 \mathrm{~mol})$ and AIBN $(0.01 \mathrm{~g})$ in toluene $(4 \mathrm{~mL})$. A colourless liquid product $(8.47 \mathrm{~g}$, theoretical yield) was obtained. ${ }^{29} \mathrm{Si}$ NMR $\left(\mathrm{C}_{6} \mathrm{D}_{6}\right) \delta$ (ppm): -11.18 (s, $\left.\mathrm{CH}_{3} \mathrm{SiCH}_{2}\right),-42.79\left(\mathrm{~s}, \mathrm{SiOCH}_{3}\right) ;{ }^{1} \mathrm{H}$ NMR $\left(\mathrm{C}_{6} \mathrm{D}_{6}\right) \delta(\mathrm{ppm})$ : $0.16\left(\mathrm{~s}, 9 \mathrm{H}, \mathrm{CH}_{3}-\mathrm{Si}\right), 0.78\left(\mathrm{~m}, 6 \mathrm{H}, \mathrm{CH}_{2}-\mathrm{Si}-\mathrm{OCH}_{3}\right), 1.02(\mathrm{~m}$, $\left.6 \mathrm{H}, \mathrm{C}_{2}-\mathrm{SiO}_{2}\right), 1.79\left(\mathrm{~m}, 6 \mathrm{H}, \mathrm{CH}_{2}-\underline{\mathrm{C}}_{2}-\mathrm{CH}_{2}\right), 2.48(\mathrm{~m}, 6 \mathrm{H}$, $\left.\mathrm{C}_{2}-\mathrm{S}\right), 2.65$ (m, 6H, S- $\left.\underline{\mathrm{H}}_{2}\right), 3.42\left(\mathrm{~s}, 27 \mathrm{H}, \mathrm{C}_{3} \mathrm{O}-\mathrm{Si}\right)$.

\subsection{Synthesis of Octasilsesquioxane with Mixed} Functional Groups

MPTMS (2.65 g, $0.0135 \mathrm{~mol})$ under argon was added to POSS-V8 (2.85 g, $0.0045 \mathrm{~mol})$ and AIBN $(0.017 \mathrm{~g}$, $\left.1 \times 10^{-4} \mathrm{~mol}\right)$ in dry toluene $(10 \mathrm{~mL})$. The mixture was stirred and refluxed for 5-h at $60{ }^{\circ} \mathrm{C}$. Modified octasilsesquioxane $(5.2 \mathrm{~g}$, yield $94.5 \%)$ containing 5.17 vinyl groups per octasilsesquioxane cage was obtained. ${ }^{1} \mathrm{H}$ NMR $\left(\mathrm{CDCl}_{3}\right) \delta$ (ppm): $0.75\left(\mathrm{~m}, \underline{\mathrm{C}}_{2}-\mathrm{Si}-\mathrm{OCH}_{3}\right), 1.17\left(\mathrm{~m}, \underline{\mathrm{C}}_{2}-\right.$ $\left.\mathrm{SiO}_{1.5}\right), 1.82\left(\mathrm{~m}, \mathrm{CH}_{2}-\mathrm{CH}_{2}-\mathrm{CH}_{2}\right), 2.65$ (m, $\left.2 \times \mathrm{C}_{2}-\mathrm{S}\right)$, $3.6\left(\mathrm{~s}, \mathrm{CH}_{3} \mathrm{O}-\mathrm{Si}\right), 6.1\left(\mathrm{~m}, \mathrm{CH}=\mathrm{CH}_{2}\right) ;{ }^{13} \mathrm{C} \mathrm{NMR}\left(\mathrm{CDCl}_{3}\right)$ $\delta$ (ppm): $8.57\left(\mathrm{CH}_{2}-\mathrm{Si}-\mathrm{OCH}_{3}\right), 12.10\left(\mathrm{CH}_{2}-\mathrm{SiO}_{1.5}\right), 22.79$ $\left(\mathrm{CH}_{2} \mathrm{CH}_{2} \mathrm{CH}_{2}\right), 25.70\left(\mathrm{~S}-\mathrm{CH}_{2}\right), 34.6 \overline{(}\left(\mathrm{CH}_{2}-\mathrm{S}\right), 50.37$ $\left(\mathrm{CH}_{3} \mathrm{O}-\mathrm{Si}\right), 125.24,127.71,128.64\left(\mathrm{CH}=\mathrm{CH}_{2}\right)$.

\section{Conclusions}

Octakis-2\{[3-(trimethoxysilyl)propyl]thio \}ethyl-octasilses qioxane (POSS-M24) was synthesized. The product is a cage oligosilsesquioxane functionalized by eight trimethoxysilyl groups bonded through a thioether bridge to the Si-atom of the silsesquioxane cage; thus, 24-hydrolysable alkoxy groups. A similar cage oligosilsesquioxane with mixed vinyl and trimethoxysilyl functions was also generated. In addition, two functionalized oligocyclosiloxanes were synthesized, tris-2,4,6-2\{[3-(trimetoksysilyl)propyl] thio \}ethyl-2,4,6-trimethylcyclotrisiloxane $\left(\mathrm{V}_{3}-\mathrm{M} 9\right)$ and tet rakis-2,4,6,8-2\{[3-(trimetoksysilyl)propyl]thio \}ethyl-2,4,6, 8-tetramethylcyclotetrasiloxane $\left(\mathrm{V}_{4}-\mathrm{M} 12\right)$, which have 9and 12-hydrolysable methoxysilyl functions, respectively. All these compounds are new precursors of silicon base materials. They were generated by thio-ene addition, which proceeds under mild conditions with a theoretical yield.

Acknowledgments The research was supported from the state funds, Project No 05000504 (Poland). Support from the Centre of Molecular and Macromolecular Studies of the Polish Academy of Sciences is also appreciated. The Authors are grateful to Professor Martel Zeldin from the University of Richmond, Virginia USA for the language improvement of this paper.

Open Access This article is distributed under the terms of the Creative Commons Attribution License which permits any use, distribution, and reproduction in any medium, provided the original author(s) and the source are credited.

\section{References}

1. C. Ni, G. Wu, Ch. Zhu, B. Yao, J. Phys. Chem. C 114, 13471 (2010)

2. D.B. Cordes, P.D. Lickiss, F. Rataboul, Chem. Rev. 110, 2081 (2010)

3. W.-B. Zhang, B. Sun, H. Li, X. Ren, J. Janoski, S. Sahoo, D.E. Dabney, Ch. Wesdemiotis, R.P. Quirk, S.Z.D. Cheng, Macromolecules 42, 7258 (2009)

4. O. Monticelli, A. Fina, A. Ullah, P. Waghmare, Macromolecules 42, 6614 (2009)

5. A.S. Kotal, T.K. Paira, T.K. Mandal, J. Polym. Sci. Part A Polym. Chem. 46, 1111 (2008)

6. J. Xu, X. Li, Ch.M. Cho, Ch.L. Toh, L. Shen, K.Y. Mya, X. Lu, Ch. He, J. Mater. Chem. 19, 4740 (2009)

7. E. Markovic, S. Clarke, J. Matisons, G.P. Simon, Macromolecules 41, 1685 (2008)

8. A. Shimojima, R. Goto, N. Atsumi, K. Kuroda, Chem. Eur. J. 14, 8500 (2008)

9. L. Zhang, Q. Yang, H. Yang, J. Liu, H. Xin, B. Mezari, P.C.M.M. Magusin, H.C.L. Abbenhuis, R.A. van Santen, C. Li, J. Mater. Chem. 18, 450 (2008)

10. L. Zhang, H.C.L. Abbenhuis, Q. Yang, Yi.-M. Wang, P.C.M.M. Magusin, B. Mezari, R.A. van Santen, C. Li, Angew. Chem. Int. Ed. 46, 5003 (2007)

11. B.P. Nair, Ch. Pavithran, Langmuir 26, 730 (2010)

12. S.-W. Kuo, F.-C. Chang, Prog. Polym. Sci. 36, 1649 (2011)

13. B.J. Hendan, H.C. Marsmann, Appl. Organometal. Chem. 13, 287 (1999)

14. P. Braunstein, J.R. Galsworthy, B.J. Hendan, H.C. Marsmann, J. Organomet. Chem. 551, 12 (1998)

15. N.L.D. Filho, R.M. Costa, F. Marangoni, Colloid. Surf. A Physicochem. Eng. Aspects 317, 625 (2008)

16. D. Gnanasekaran, K. Madhavan, B.S.R. Reddy, J. Sci. Ind. Res. 68, 437 (2009)

17. R.M. Laine, J. Mater. Chem 15, 3725 (2005)

18. K. Rozga-Wijas, J. Chojnowski, J. Scibiorek, J. Mater. Chem. 15, $2383(2005)$

19. C. Sanchez, G.J.D.A.A. Solier-Illia, R. Ribot, D. Grosso, Competes Rendus Chimie 6, 1131 (2003)

20. A. Sayari, Chem. Mater. 16, 1756 (2004)

21. S. Udayakumar, H.L. Shim, V. Raman, D.W. Park, Micropor. Mesopor. Mater. 129, 149 (2010) 
22. K. Viswanathan, H. Ozhalici, C.L. Elkins, Ch. Heisey, T.C. Ward, T.E. Long, Langmuir 22, 1099 (2006)

23. J.S. Parent, M.I. Mrkoci, S.L. Hennigar, Plast Rubber Compos 32, 114 (2003)

24. B.S. Flavel, M.R. Nussino, J.S. Quinton, J.G. Shapter, J. Nanoparticle Res. 11, 2013 (2009)

25. K. Rózga-Wijas, J. Chojnowski, S. Boileau, J. Polym. Sci. Part. A Polym. Chem. 35, 879 (1997)

26. Ch. Rissing, D.Y. Son, Organometallics 28, 3167 (2009)

27. Ch. Rissing, D.Y. Son, Organometallics 27, 5394 (2008)

28. W.-B. Zhang, Y. Li, X. Li, X. Dong, X. Yu, Ch.-L. Wang, Ch. Wesdemiotis, R.P. Quirk, S.Z.D. Cheng, Macromolecules 44, 2589 (2011)

29. X. Yu, S. Zhong, X. Li, Y. Tu, S. Yang, R.M. Horn, Ch. Ni, D.J. Pochan, R.P. Quirk, Ch. Wesdemiotis, W.-B. Zhang, S.Z.D. Cheng, J. Am. Chem. Soc. 132, 16741 (2010)
30. B. Yu, X. Jiang, N. Qin, J. Yin, Chem. Commun. 47, 12110 (2011)

31. T.S. Clark, Ch.E. Hoyle, S. Nazarenko, J. Coat. Technol. Res. 5, 345 (2008)

32. J.A. Crowe-Willoughby, J. Genzer, Adv. Funct. Mater. 19, 460 (2009)

33. K. Rózga-Wijas, J. Chojnowski, T. Zundel, S. Boileau, Macromolecules 26, 271 (1996)

34. M. Scibiorek, N. Gladkova, J. Chojnowski, Polymer Bull. 44, 377 (2000)

35. L. Herczynska, L. Lestel, S. Boileau, W. Fortuniak, J. Chojnowski, Eur. Polym. J. 35, 1115 (1999)

36. K. Rózga-Wijas, J. Chojnowski, W. Fortuniak, M. Ścibiorek, Z. Michalska, Ł. Rogalski, J. Mater. Chem. 13, 2301 (2003)

37. T. Takiguchi, M. Sakurai, T. Kishi, J. Ichimura, Y. Izuka, J. Org. Chem. 25, 310 (1960) 